Research Paper:

\title{
The Effects of Relaxing Music on Life Distress and Maternal-fetal Attachment in Pregnant Women
}

\author{
Mona Shokri Shamsi ${ }^{1}$, Anahita Khodabakhshi-Koolaee ${ }^{2^{*}}$ (D), Mohammad Reza Falsafinejad ${ }^{3}$ (D) \\ 1. Department of Counseling, Faculty of Humanities and Social Sciences, Branch of Science and Research, Islamic Azad University, Tehran, Iran. \\ 2. Department of Psychology and Education Sciences, Faculty of Humanities, Khatam University, Tehran, Iran. \\ 3. Department of Assessment and Measurement, Faculty of Psychology and Educational Sciences, Aallameh Tabataba 'i University, Tehran, Iran.
}

\begin{tabular}{|l|l|l|l}
\hline $\begin{array}{c}\text { Use your device to scan } \\
\text { and read the article online }\end{array}$ & $\begin{array}{l}\text { Citeation: Shokri Shams, M., Khodabakhshi-Koolaee, A., \& Falsafinejad, M. R., 2021. The Effects of Relaxing Music on Life } \\
\text { Distress and Maternal-fetal Attachment in Pregnant Women. Journal of Client-Centered Nursing Care, 7(1), pp. 1-8. https://doi. } \\
\text { org/10.32598/JCCNC.7.1.33.14 }\end{array}$ \\
doifhttps://doi.org/10.32598/JCCNC.7.1.33.14
\end{tabular}

(c) (1)

Article info:

Received: 30 Nov 2020

Accepted: 14 Dec 2020

Published: 01 Feb 2021

Keywords:

Music therapy,

Psychological distress,

Maternal-fetal

relationship, Pregnancy

\section{A B S T R A C T}

Background: Although pregnancy and motherhood are enjoyable experiences, they are associated with numerous biopsychological changes requiring adaptation. The present study aimed to assess the effects of relaxing music on life distress and Maternal-Fetal Attachment (MFA) in pregnant women.

Methods: This was a quasi-experimental study with a pre-test, post-test and a control group design. The research population included all Iranian pregnant women referring to Laleh Hospital in Tehran City, Iran, in 2020. In total, 30 women were selected using the convenience sampling method and randomly assigned into the intervention and control groups ( $\mathrm{n}=15 /$ group). The required data were collected using the Life Distress Inventory (LDI) and the MaternalFetal Attachment Scale (MFAS). The intervention group listened to relaxing music for twelve 45-50-minute sessions in the morning and during routine midwifery visits; however, the controls received no intervention. The collected data were analyzed using Multivariate Analysis of Covariance (MANCOVA) in SPSS V. 22.

Results: The obtained results indicated that the intervention group reported a lower level of life distress in the post-test, compared to the controls $(\mathrm{P}=0.0001, \mathrm{~F}=15.860)$. The intervention group also achieved a higher mean score on MFA, than the control group ( $\mathrm{P}=0.0001, \mathrm{~F}=35.872)$.

Conclusion: According to the present research findings, reproductive health and nursing professionals, and psychologists would recommend music as a complementary therapy to reduce stress and distress experienced by expecting mothers and to improve MFA.

\footnotetext{
* Corresponding Author:
}

Anahita Khodabakhshi-Koolaee, PhD.

Address: Department of Psychology and Education Sciences, Faculty of Humanities, Khatam University, Tehran, Iran.

Tel: +98 (21) 89174119

E-mail: a.khodabakhshid@khatam.ac.ir 


\section{Highlights}

- Pregnancy is a period of joy that coincides with sorrow. Pregnant women experience different feelings and emotions.

- The stresses experienced by pregnant mothers can lead to psychological distress and physical problems.

- Art, music, leisure, and peace of mind can help reduce stress in pregnant women. It also provides an opportunity for the mother to further reflect on her relationship with the fetus.

- The present research results suggested that soothing non-vocal music can help reduce distress in pregnant women and increase their attachment to their fetus.

\section{Plain Language Summary}

Music therapy is an art and psychological intervention, i.e. used to treat many physical and mental illnesses. Music can help reduce anxiety, depression, high blood pressure, and heartbeat, as well as better sleep in pregnant women. Also, music can create moments of joy and positive emotions in these women. The results of this study indicated that after 12 sessions of music therapy, the life distress of pregnant women declined, while their maternal-fetal attachment increased.

\section{Introduction}

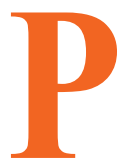

regnancy and motherhood as essential life events of women are associated with some biopsychological alternations (Dau, Callinan \& Smith 2019). Pregnancy, while being an enjoyable experience, is among the periods of life with high levels of worry and anxiety for women. Furthermore, life changes and distresses reciprocally increase anxiety and stress in expecting mothers (Garcia-Gozalez et al. 2018). Anxiety and life distress may lead to preterm birth, increased odds of cesarean sections, and low birth weight (Chang et al. 2015). Accordingly, pregnancy can be considered among the most significant periods of marital life; during which, numerous changes occur not only physically but also socially and psychologically. Besides, daily stresses associated with physical and hormonal changes can lead to anxious responses in the mother (Davoudi, Khodabakhshi-Kolaee \& Falsafinejad 2018). Research indicated that depression, anxiety, stress, and long-term use of drugs lead to miscarriage, low birth weight, and physical problems in pregnant women (Ban et al. 2012; Fekadu Dadi, Miller \& Mwanri 2020). Accordingly, previous studies suggested that the stress experienced by the mother during pregnancy prevents a strong bond between mother and fetus (Srivastava \& Bhatnagar 2020; Ghelichi, Roshan \& Khodabakhshi Kolaee 2017).
Maternal-Fetal Attachment (MFA) and reduced stress, anxiety, and depression during pregnancy affect the formation and establishment of safe and healthy childmother attachment (Alhusen 2008). MFA during pregnancy refers to a process in which a pregnant woman experiences emotional experiences and interaction with her fetus, and developing a maternal identity (Cranley 1981). MFA depends on the support of the woman during pregnancy; e.g. the relationship with her mother and husband. It is the first and most important relationship that predicts the manner and quality of the relationship between the mother and child (Rodríguez, Carrascal \& Castaño 2019). Cranley (1981) claimed that certain behaviors, such as smoking and alcohol cessation, proper nutrition, exercise, continuing prenatal care, a desire to get to know the fetus, and attending childbirth preparatory classes, lead to satisfactory pregnancy outcomes, promoted maternal and infant health, and taking maternal responsibility (Cranley 1981). MFA-related behaviors are divided into 5 general categories, including role-taking, the differentiation of self from the fetus, the giving of self, attributing characteristics and intentions to the fetus, and interaction with the fetus. Mothers with lower levels of attachment also report higher levels of stress and depression, which can lead to adverse pregnancy outcomes (Cunen et al. 2017; Abasi et al. 2020).

There is a growing interest in using non-pharmacological and complementary methods to reduce stress and anxiety. One of such methods is using relaxing and 
non-vocal music (Khodabakhshi-Koolaee, Zahmatkesh \& Barzeghar Khezri 2018). Music therapy is the systematic use of music to create positive changes in behavioral and physiological symptoms by reducing heart rate, respiration rate, and blood pressure, as well as decreasing metabolic rate, oxygen consumption, muscle stiffness, and so on (Aisyah \& Hardjanti 2019). Numerous studies reported that music can help reduce anxiety, psychological stress, and blood pressure in pregnant women (Shin \& Kim 2011; Aisyah \& Hardjanti 2019).

Relaxing music is a low-cost method that can be easily played for women attending face-to-face sessions. Such an approach can help reduce their life distress and worries and provide an opportunity for them to further reflect on their relationship with the fetus and feel more positive about it. Accordingly, the present study aimed to evaluate the effects of relaxing music on life distress and MFA in Iranian pregnant women.

\section{Materials and Methods}

This was a quasi-experimental study with a pre-test, post-test and a control group design. Playing relaxing and non-vocal music was considered as the independent variable and the distress of life and MFA were observed as dependent variables. The research population included all pregnant women who were referred to Laleh Hospital in Tehran City, Iran, in 2020. It is a general hospital located in the west of Tehran, i.e. equipped with maternity wards and labor rooms, Neonatal Intensive Care Unit (NICU), and neonatal wards. The research sample was 30 women who were volunteers to participate in this study. They were selected using the convenience sampling technique and randomly assigned into the intervention and control groups ( $\mathrm{n}=15 /$ group). The inclusion criteria were as follows: women referring to Laleh Hospital for midwifery examinations; the second trimester of pregnancy, and women who were not prohibited from attending music sessions according to the diagnosis of a gynecologist. The exclusion criteria were absence from $\geq 2$ music therapy sessions and concurrently attending other relaxing classes, such as yoga, meditation, or music-based interventions.

The required data were collected using the Life Distress Inventory (LDI) and the Maternal-Fetal Attachment Scale (MFAS). The LDI was developed by Yoshioka and Shibusawa (2002); it is used to measure the level of life distress experienced by an individual. The inventory has 18 items and 4 subscales. These subscales include social functioning, life satisfaction, finances and employment, and marital distress. Each item of the in- ventory is scored using a 7-point Likert-type scale that ranges from $1=$ no distress to $7=$ the highest distress. The minimum and maximum scores of the inventory are 18 and 126, respectively. Higher scores denote greater distress. Researchers have reported a satisfactory construct validity for this scale. Besides, its reliability, using Cronbach's alpha coefficient, was reported as 0.84 (Yoshioka $\&$ Shibusawa 2002). The Persian version of the inventory was administered to the participants in this study and its reliability was reported to be 0.88 using Cronbach's alpha coefficient.

The MFAS was developed by Cranley (1981). The scale contains 24 items and 5 subscales; role-taking, the differentiation of self from the fetus, the giving of self, attributing characteristics and intentions to the fetus, and interaction with the fetus. The items are scored using a 5-point Likert-type scale (1 to 5). The total score of the scale ranges from 24 to 120 , with higher scores indicating a higher MFA. The face and content validity indexes of the scale were reported to be within acceptable levels. Besides, Cranley (1981) reported Cronbach's alpha coefficient of the scale as 0.85 . The content validity of the Persian version of the scale was assessed and confirmed; its reliability was assessed using Cronbach's coefficient as equal to 0.83 (Ghelichi et al. 2017).

The training sessions were held for the study participants in the intervention group for 6 weeks on Sundays and Tuesdays ( $\mathrm{n}=12$ sessions) in a hall prepared for this purpose in Laleh Hospital. Each session was held before noon and lasted about 45 to 50 minutes. The intervention was implemented only for the participants in the intervention group. The music tracks played in the intervention sessions were selected from an album by Arnd Stein, a German psychologist, and musicologist, under his official permission. In this research, the music was used as a therapy and was delivered in a group (De Witte et al. 2020). The same album was used in another study (Khodabakhshi-Koolaee et al. 2018). The reason for choosing Stein's music is that his music was composed for relaxation. Table 1 summarizes the content of the intervention sessions.

Only the intervention group listened to relaxing music and the controls received no intervention. Upon completing the therapy sessions, to evaluate the effects of the provided intervention, all study participants completed the same questionnaires as the post-test. The chart of the study process is shown in Figure 1. 
Table 1. Music sound tracks played in the intervention sessions

\begin{tabular}{cll}
\hline Session & Composer & Tracks \\
\hline First & Arnd Stien & Beautiful day \\
\hline Second & Arnd Stien & Magical sound \\
\hline Third & Arnd Stien & Swinging soul \\
\hline Fourth & Arnd Stien & Silent space \\
\hline Fifth & Arnd Stien & Hypnotic circle \\
\hline Sixth & Arnd Stien & Sweet passion \\
\hline Seventh & Arnd Stien & Good feeling \\
\hline Eighth & Arnd Stien & Neubeginn \\
\hline Ninths & Arnd Stien & Sudseetraume \\
\hline Tenth & Arnd Stien & Am bergsee \\
\hline Eleventh & Arnd Stien & Impression \\
\hline Twelfth & Arnd Stien & Gedankenflug \\
\hline
\end{tabular}

Finally, the collected data were analyzed using the Multivariate Analysis of Covariance (MANCOVA) and Least Significant Difference (LSD) test in SPSS V. 22.

\section{Results}

The experimental group members' Mean \pm SD age was $30.53 \pm 2.05$ years and ranged from 20 to 35 years. Besides, the Mean \pm SD age of the controls was $31.06 \pm 2.18$ years and fell within the range of 20 to 35 years. There was no significant difference between the two groups in terms of demographic characteristics (Table 2).

Table 3 presents the descriptive statistics of life distress and MFA in the study groups (intervention \& control) at the pre-test and post-test steps. There was no significant difference between the mean pre-test scores of the study groups.

The Levene's test data indicated that the values of life distress $\left(\mathrm{F}=12.06, \mathrm{df}_{1}=1, \& \mathrm{df}_{2}=27\right)$ and MFA $(\mathrm{F}=8.60$, $\left.\mathrm{df}_{1}=1, \& \mathrm{df}_{2}=27\right)(\mathrm{P}>0.05)$ were not significant. There-

Table 2. The study participants' demographic characteristics

\begin{tabular}{|c|c|c|c|c|}
\hline \multirow{2}{*}{ Variable } & \multirow{2}{*}{ Categories } & \multicolumn{2}{|c|}{ No. (\%) } & \multirow{2}{*}{$\mathbf{P}$} \\
\hline & & Control & Intervention & \\
\hline \multirow{3}{*}{ Age, $y$} & $20-25$ & $4(26.7)$ & $5(33.3)$ & \multirow{3}{*}{0.853} \\
\hline & $26-30$ & $5(33.3)$ & $6(40.0)$ & \\
\hline & $31-35$ & $6(40.0)$ & $4(26.7)$ & \\
\hline \multirow{5}{*}{ Educational level } & Diploma & $5(33.3)$ & $5(33.3)$ & \multirow{5}{*}{0.457} \\
\hline & Associate's degree/College & $5(33.3)$ & $4(26.7)$ & \\
\hline & & & & \\
\hline & BA & $3(20.0)$ & $3(20.0)$ & \\
\hline & MA & $2(13.4)$ & $3(20.0)$ & \\
\hline
\end{tabular}




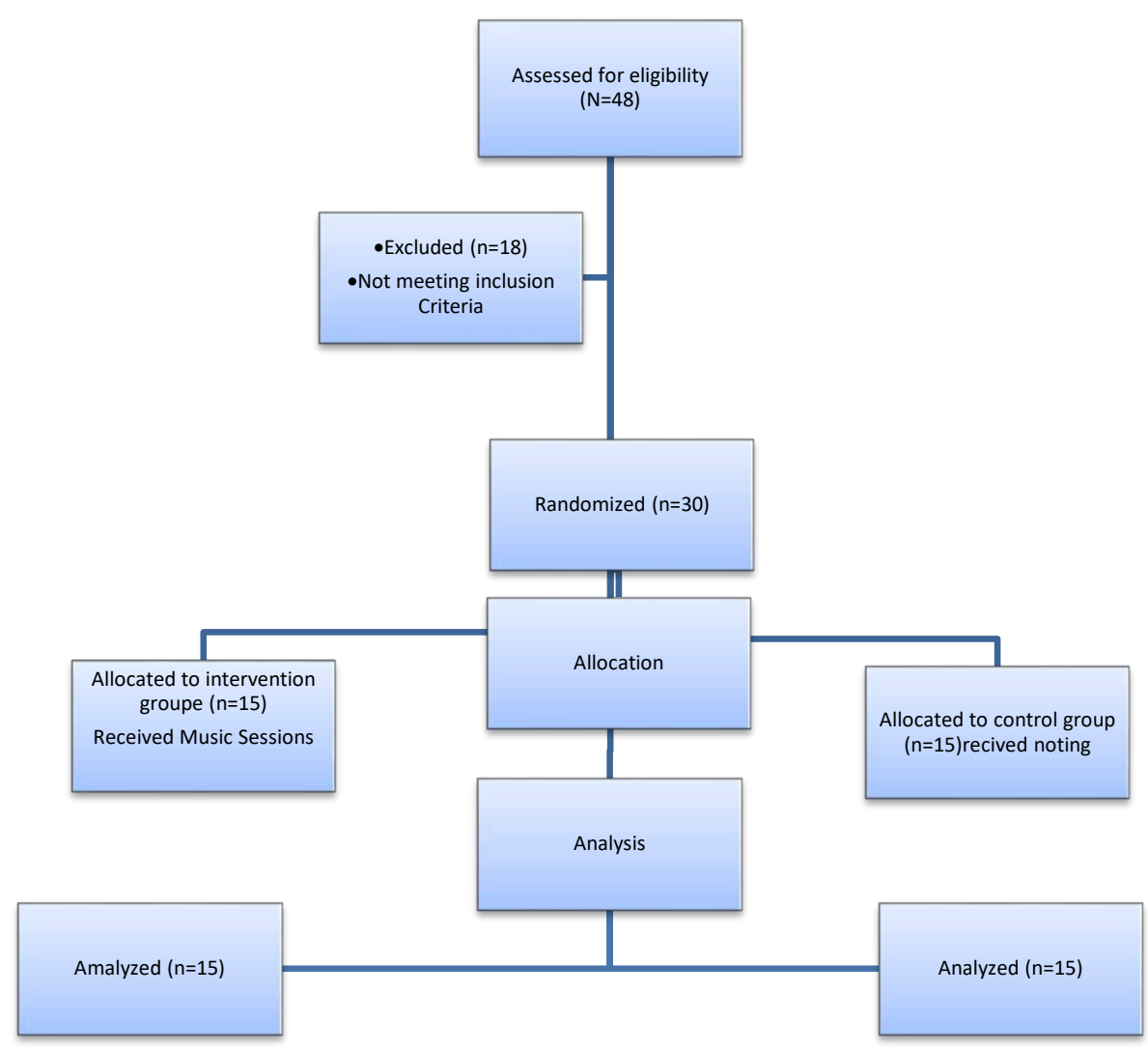

Figure 1. The flow diagram of the study process

Client- Centered Nursing Care

fore, the assumption of the homogeneity of variance was confirmed. The values of the Box's M test for the research variables $(\mathrm{F}=3.669, \mathrm{P}=0.336)$ were not significant $(\mathrm{P}>0.05)$; thus, the assumption of the homogeneity of all variances in the covariance matrix was confirmed.

As per Table 4, post-test scores were considered as the dependent variables, the group variable (at two levels) as an independent variable, and the pre-test scores as pre-test effect variables were incorporated in the MANCOVA.

According to Table 4, there was a significant difference in the linear composition of MFA scores in the explored pregnant women by group (Sig. $=0.0001, \mathrm{~F}=25.364$, Wilkes lambda $=0.330$ ). Moreover, the ETA findings suggested that $67 \%$ of the variances of the dependent variables could be explained by the group effects. Therefore, changes in the independent variable were significant on at least one of the dependent variables. To evaluate the patterns of differences per dependent variable, univariate Analysis of Covariance (ANCOVA) was used in the context of MANCOVA.

As per Table 5, there was a significant difference in the linear composition of life distress and MFA scores in the studied pregnant women by the group. Besides,
Eta squared revealed that $37.9 \%$ of the variances in life distress and $57.9 \%$ of the variances in MFA in the study subjects can be explained by the group effects.

\section{Discussion}

Music is a form of art that conveys human feelings, emotions, perceptions, and cognition without the need for speech and words. Human use of music has been easy and accessible. This is because rhythm and melody, as the two basic elements of music, have existed in human nature. Besides, prior research reported that music therapy serves as a natural anti-stress and anti-depression factor. A piece of music chosen carefully can affect mood and reduce stress (Altenmüller \& Schlaug 2015).

The present study data demonstrated that relaxing music was effective in reducing the life distress of pregnant women, as suggested by other studies (e.g. GarciaGonzales 2018; Chang et al. 2015). Furthermore, Shin and Kim (2011) argued that the participation of pregnant women in music therapy sessions has reduced their anxiety and stress. Another study documented that music therapy can generally reduce stress and improve the blood pressure status of pregnant women (Aisyah \& Hardjanti 2019). Furthermore, music can divert attention 
Table 3. Descriptive statistics concerning life distress and MFA in the study samples

\begin{tabular}{|c|c|c|c|}
\hline \multirow{2}{*}{ Dependent Variable } & \multirow{2}{*}{ Group } & \multicolumn{2}{|c|}{ Mean $\pm S D$} \\
\hline & & Pre-test & Post-test \\
\hline \multirow{2}{*}{ Life distress } & Intervention & $58.60 \pm 8.87$ & $46.73 \pm 7.65$ \\
\hline & Control & $61.13 \pm 8.50$ & $60.93 \pm 9.51$ \\
\hline \multirow{2}{*}{ Interaction with the fetus } & Intervention & $15.53 \pm 4.35$ & $19.40 \pm 3.35$ \\
\hline & Control & $16.73 \pm 3.89$ & $16.86 \pm 3.56$ \\
\hline \multirow{2}{*}{$\begin{array}{l}\text { The differentiation of self from the } \\
\text { fetus }\end{array}$} & Intervention & $14.73 \pm 4.57$ & $16.60 \pm 3.35$ \\
\hline & Control & $15.80 \pm 4.31$ & $15.73 \pm 4.02$ \\
\hline \multirow{2}{*}{ Role-taking } & Intervention & $14.80 \pm 3.12$ & $19.06 \pm 2.91$ \\
\hline & Control & $15.20 \pm 2.51$ & $15.53 \pm 2.58$ \\
\hline \multirow{2}{*}{$\begin{array}{l}\text { Attributing characteristics and inten- } \\
\text { tions to the fetus }\end{array}$} & Intervention & $17.80 \pm 2.73$ & $18.53 \pm 2.50$ \\
\hline & Control & $16.53 \pm 2.58$ & $16.53 \pm 2.53$ \\
\hline \multirow{2}{*}{ The giving of self } & Intervention & $19.06 \pm 2.52$ & $22.73 \pm 1.94$ \\
\hline & Control & $18.20 \pm 2.78$ & $18.53 \pm 2.77$ \\
\hline \multirow{2}{*}{ MFA } & Intervention & $81.93 \pm 9.49$ & $96.33 \pm 8.41$ \\
\hline & Control & $82.46 \pm 8.54$ & $83.20 \pm 9.08$ \\
\hline
\end{tabular}

Table 4. The obtained MANCOVA data

\begin{tabular}{ccccccc}
\hline Test & Statistic & F & Hypothesis df & Error df & Sig. & Eta Squared \\
\hline Pillai's trace test & 0.670 & 25.364 & 2 & 25 & 0.0001 & 0.670 \\
\hline Wilks' lambda test & 0.330 & 25.364 & 2 & 25 & 0.0001 & 0.670 \\
\hline Hotelling's trace test & 2.029 & 25.364 & 2 & 25 & 0.0001 & 0.670 \\
\hline Roy's largest root & 2.029 & 25.364 & 2 & 25 & 0.0001 & 0.670 \\
\hline
\end{tabular}

Table 5. The results of one-way ANCOVA

\begin{tabular}{cccccccc}
\hline Variable & Groups & SS & df & MS & F & P* & Eta \\
\hline \multirow{2}{*}{ Life distress } & Pre-test & 996.526 & 1 & 996.526 & & & \\
& Group effect & 1171.832 & 1 & 1171.832 & 13.487 & 0.001 & 0.342 \\
& Error & 1921.069 & 27 & 73.887 & & & \\
MFA & Pre-test & 263.097 & 1 & 263.097 & & 0.015 & 0.208 \\
& Group effect & 1375.459 & 1 & 1375.459 & 644 & & \\
\hline
\end{tabular}

df: degree of freedom; SS: Sum of Squares; MS: Mean of Squares; ${ }^{*} \mathrm{P}<0.01$.

Client- Centered Nursing Care 
from stress to other issues (Chang et al. 2015; Belloeil et al. 2020). Generally, music reduces gestational anxiety, severe heart rate, perceived stress, and hypertension (Teckenberg-Jansson et al. 2019; van Willenswaard et al. 2017; Cao et al. 2016).

This study also found that relaxing music could effectively enhance MFA in pregnant women. Music has been suggested to have great power in creating a feeling of calmness in pregnant women and helps the motherfetus relationship (Chang et al. 2015). Another study revealed that music can help the mother to effectively communicate with the fetus and give him/her the necessary comfort (Shin \& Kim 2011). In other words, pregnant women feel relaxed by listening to music; thus, the nervous system functions more effectively and regularly and can improve the mother-fetus relationship (Chang et al. 2015; Shin \& Kim 2011). Paying attention to the needs of pregnant women and their mental health during pregnancy is crucial. The more insecure the attachment and the lower the quality of the mother-fetus relationship, the less the MFA (Branjerdporn et al. 2020).

Nivedhitha and Geetha (2020) stated that leisure activities are essential to increase the mental health of pregnant women. They examined the effect of studying on fetal attachment during pregnancy. The relevant results indicated that when pregnant women are studying, they experience mental vitality. Therefore, studying can be used as a manner to spend leisure time and increase their mental health, and bond with their child (Nivedhitha \& Geetha 2020).

The present study was conducted with some limitations. First, the research sample was limited to pregnant women referring to Laleh Hospital in Tehran in the summer of 2020. Besides, given the prevalence of the COVID-19 pandemic, the intervention sessions were held in full compliance with health protocols; therefore, it was impossible to perform a follow-up test to evaluate the retention effects of the intervention program.

\section{Conclusion}

The present study results suggested that music can help pregnant women in the second trimester of pregnancy to reduce life distress and enable them to reflect on their relationship with their fetus; subsequently, they feel content following the relaxation induced by listing to music. Finally, music therapy, as a low-cost, group-based approach, can help nurses, midwives, and psychologists working in medical centers and maternity wards create relaxing moments for expecting mothers.

\section{Ethical Considerations}

\section{Compliance with ethical guidelines}

This study was approved by the Ethics Committee of Islamic Azad University, Science, and Research Branch, Tehran (Code: IR.IAU.SRB.REC.1399.081). Before conducting the study, written permission was obtained from the University's Ethics Committee and the necessary arrangements were made. Informed written consent was obtained from the study subjects. The research participants were assured that their transportation costs would be paid by the researcher.

\section{Funding}

This study was extracted from a MSc. thesis of the first author at the Department of Counseling, Faculty of Humanities and Social Sciences, Branch of Science and Research, Islamic Azad University.

\section{Authors' contributions}

All authors equally contributed to preparing this article.

\section{Conflict of interest}

The authors declared no conflicts of interest.

\section{Acknowledgments}

The authors would like to thank the participants and also managers and staff of Laleh Hospital in Tehran.

\section{References}

Alhusen, J. L., 2008. A literature update on maternal-fetal attachment. Journal of Obstetric, Gynecologic \& Neonatal Nursing, 37(3), pp. 315-28. [DOI:10.1111/j.1552-6909.2008.00241.x] [PMID] [PMCID]

Altenmüller, E. \& Schlaug, G., 2015. Apollo's gift: New aspects of neurologic music therapy. Progress in Brain Research, 217, pp. 237-52. [DOI:10.1016/bs.pbr.2014.11.029] [PMID] [PMCID]

Aisyah, A., \& Hardjanti, T. S., 2019. The effect of music therapy for pregnant women: A literature review. Proceedings of the International Conference on Applied Science and Health, 4, pp. 403-7. https://www.semanticscholar.org/paper/THE-EFFECT-OF-MUSIC-THERAPY-FOR-PREGNANT-WOMEN\%3A-A-Aisyah-Hardjanti/41d474af51d4cdaa3630fcc4c971ba410603dac8

Ban, L., et al. 2012. Live and non-live pregnancy outcomes among women with depression and anxiety: A population- 
based study. PLoS One, 7(8), p. e43462. [DOI:10.1371/journal. pone.0043462] [PMID] [PMCID]

Belloeil, V., et al., 2020. Impact of music therapy before first-trimester instrumental termination of pregnancy: A randomised controlled trial. BJOG: An International Journal of Obstetrics and Gynaecology, 127(6), pp. 738-45. [DOI:10.1111/14710528.16102] [PMID]

Branjerdporn, G., et al., 2020. Prenatal predictors of maternalinfant attachment. Canadian Journal of Occupational Therapy, 87(4), pp. 265-77. [DOI:10.1177/0008417420941781] [PMID]

Cao, S., et al., 2016. Music therapy improves pregnancy-induced hypertension treatment efficacy. International Journal of Clinical and Experimental Medicine, 9(5), pp. 8833-8. http:/ / www.ijcem. com/files/ijcem0021741.pdf

Chang, H. C., et al., 2015. The effects of music listening on psychosocial stress and maternal-fetal attachment during pregnancy. Complementary Therapies in Medicine, 23(4), pp. 509-15. [DOI:10.1016/j.ctim.2015.05.002] [PMID]

Cranley, M. S., 1981. Development of a tool for the measurement of maternal attachment during pregnancy. Nursing Research 30(5), pp. 281-4. [DOI:10.1097/00006199-198109000-00008] [PMID]

Cunen, N. B., et al., 2017. A narrative review of interventions addressing the parental-fetal relationship. Women and Birth 30(4), pp. e141-51. [DOI:10.1016/j.wombi.2016.11.005] [PMID]

Dau, A. L., Callinan, L. S., \& Smith, M. V., 2019. An examination of the impact of maternal fetal attachment, postpartum depressive symptoms and parenting stress on maternal sensitivity. Infant Behavior and Development, 54, pp. 99-107. [DOI:10.1016/j.infbeh.2019.01.001] [PMID]

Davoudi, Z., Khodabakhshi-Kolaee, A., \& Falsafinejad, M., 2018. The Effectiveness of training of self-help program toward the parenthood on worry in pregnancy period among the nulliparous women. Journal of Health Literacy, 3(1), pp. 61-71. http:/ / eprints.mums.ac.ir/9989/

de los Ángeles Gázquez Rodríguez, M., Carrascal, G. C., \& Castaño, J. H. O., 2019. Maternal-fetal bonding: A concept analysis. Revista Habanera de Ciencias Médicas, 18(6), pp. 969-82. https://www.medigraphic.com/cgi-bin/new/resumenI cgi?IDARTICULO=95129

de Witte, M., et al., 2020. Effects of music interventions on stressrelated outcomes: A systematic review and two meta-analyses. Health Psychology Review, 14(2), pp. 294-324. [DOI:10.1080 /17437199.2019.1627897] [PMID]

Fekadu Dadi, A., Miller, E. R., \& Mwanri, L., 2020. Antenatal depression and its association with adverse birth outcomes in low and middle-income countries: A systematic review and meta-analysis. PloS One, 15(1), p. e0227323. [DOI:10.1371/ journal.pone.0227323] [PMID] [PMCID]

Garcia-Gonzalez, J., et al., 2018. State-trait anxiety levels during pregnancy and foetal parameters following intervention with music therapy. Journal of Affective Disorders, 232, pp. 17-22. [DOI:10.1016/j.jad.2018.02.008] [PMID]

Ghelichi, F., Roshan, R., \& Khodabakhshi Kolaee, A., 2017. [Comparing of maternal-fetal attachment and pregnancy anxiety in surrogate women and normal pregnancy (Persian)]. The Iranian Journal of Obstetrics, Gynecology and Infertility, 19(39), pp. 46-53. [DOI:10.22038/IJOGI.2017.8421]
Abasi, E., et al. 2020. Evaluating the effect of prenatal interventions on maternalâ foetal attachment: A systematic review and meta-analysis. Nursing Open, 8(1), pp. 4-16. [DOI:10.1002/ nop2.648] [PMID] [PMCID]

Khodabakhshi-Koolaee, A., Zahmatkesh, M., \& Barzeghar Khezri, R., 2018. [The effect of relaxation and instrumental music by Arnd Stein on quality of sleep and happiness among ageing women (Persian)]. Journal of Torbat Heydariyeh University of Medical Sciences, 5(4), pp. 46-53. http:/ /jms.thums.ac.ir/ article-1-466-en.html

Nivedhitha, K. S., \& Geetha, S. N., 2020. Leisure reading experience promoting prenatal attachment among pregnant women: A moderated mediation model. Journal of Leisure Research, 24, pp. 1-29. [DOI:10.1080/00222216.2020.1834891]

Rodríguez, M. D., Carrascal, G. C., \& Castaño, J. H., 2019. Maternal-fetal bonding: A concept analysis. Revista Habanera de Ciencias Médicas, 18(6), pp. 969-82. https://www.medigraphic.com/cgi-bin/new/resumenI.cgi?IDARTICULO=95129

Shin, H. S., \& Kim, J. H., 2011. Music therapy on anxiety, stress and maternal-fetal attachment in pregnant women during transvaginal ultrasound. Asian Nursing Research, 5(1), pp. 19-27. [DOI:10.1016/S1976-1317(11)60010-8]

Srivastava, A., \& Bhatnagar, P., 2020. Maternal foetal attachment and perceived stress during pregnancy. International Journal of Reproduction, Contraception, Obstetrics and Gynecology, 8(9), pp. 3750-6. [DOI:10.18203/2320-1770.ijrcog20193810]

Teckenberg-Jansson, P., et al., 2019. Effects of live music therapy on heart rate variability and self-reported stress and anxiety among hospitalized pregnant women: A randomized controlled trial. Nordic Journal of Music Therapy, 28(1), pp. 7-26. [D OI:10.1080/08098131.2018.1546223]

van Willenswaard, K. C., et al., 2017. Music interventions to reduce stress and anxiety in pregnancy: A systematic review and meta-analysis. BMC Psychiatry, 17(1), p. 271. [DOI:10.1186/ s12888-017-1432-x] [PMID] [PMCID]

Yoshioka, M. R., \& Shibusawa, T., 2002. The life distress inventory: A psychometric evaluation. Research on Social Work Practice, 12(6), pp. 752-67. [DOI:10.1177/104973102237473] 